\title{
INTERthesis
}

\section{DESENHOS DE RESISTÊNCIA NA CIDADE VIDEOVIGIADA: CONSIDERACÕES SOBRE A RECUSA CRIATIVA NO CONTEXTO BIOPOLITICO CONTEMPORÂNEO}

\section{Resumo:}

Eledison de Souza Sampaio ${ }^{1}$

O texto tece considerações sobre o desenho de resistência na sociedade biopolítica contemporânea. Em um primeiro momento, retoma uma discussão sobre as "sociedades disciplinares" e "sociedades de controle", para, posteriormente, colocar a questão da resistência criativa como fluxos insurgentes nas cidades brasileiras. Com isso, será possível demarcar alguns movimentos políticos atuais que apontam para o caráter ambivalente da sociedade biopolítica contemporânea.

Palavras-chave: Disciplina. Controle. Videovigilância. Desenhos de Resistência. Cidade contemporânea.

\section{INTRODUÇÃO}

Seguindo uma perspectiva interdisciplinar, este artigo elabora o tema da resistência no contexto biopolítico contemporâneo. Para tanto, retoma uma leitura minuciosa das obras de Michel Foucault (1988; 2008; 2013), sobretudo aquelas onde o filósofo anuncia, com seus movimentos conceituais, aquilo que Gilles Deleuze (1992) veio a denominar como sociedades de controle.

Para dar conta deste paradigma complexo e escorregadio, convém incrementar uma investigação interdisciplinar da problemática que envolve os processos de comunicação e a produção de subjetividades na sociedade contemporânea. Como se sabe, quando os autores citados - Michel Foucault e Gilles Deleuze - elaboram suas metodologias para o estudo do poder, expressam um ponto de confluência, uma zona de intersecção, que é a que nos interessa neste momento. Trata-se, em ambos, de uma avaliação ambivalente da sociedade, ou melhor, de uma postura que emparelha as tentativas de homogeneização e os esforços de diferenciação como condições intrínsecas ao sistema político

\footnotetext{
${ }^{1}$ Mestre em Desenho, Cultura e Interatividade pela Universidade Estadual de Feira de Santana. Bacharel em Humanidades pela Universidade Federal da Bahia, Salvador, BA. E-mail: eledisonsampaio@hotmail.com
} 
contemporâneo. Neste caso, vale destacar que a perspectiva ultrapassa a importante contribuição marxiana - crítica ao modus operandi da sociedade capitalista, sobretudo à violência de classe -, mas não a descarta, já que, por detrás das novas formas de poder, encontram-se velhas condições de dominação e violência, principalmente em países pós-coloniais, a exemplo do Brasil.

Convém ressaltar que a abordagem possui um caráter dual, pois concebe alguns efeitos antidemocráticos da videovigilância na cidade contemporânea, mas, por outro lado, registra importantes movimentos de resistência. Grosso modo, o poder assimila em suas dinâmicas relacionais as questões do controle e da resistência criativa (DELEUZE, 1992). Tais procedimentos de recusa, aqui denominados como desenhos de resistência, indicam uma potência que é da ordem da criação e do movimento, operando enquanto política desregrada e transgressora que articula o visível e o invisível em cada contexto de multiplicidades.

$O$ texto que segue procura ressaltar um tipo de olhar criativo sobre a cidade que sobrevive e que se desenvolve à revelia das ameaças constantes de homogeneização e da globalização - processos que possuem relação íntima com o modo de funcionamento dos regimes tecnológicos de vigilância e controle das sociedades atuais.

\section{DA DISCIPLINA AO CONTROLE}

No conhecido texto Vigiar e Punir, Michel Foucault (2013) apresenta um itinerário analítico sobre duas formas diferentes de operação do poder e dos mecanismos de dominação. Se nas sociedades de soberania o poder postula sobre a vida e a morte dos súditos, impondo o terror como estratégia de obediência, nas sociedades disciplinares ocorre uma espécie de "suavização" das práticas de poder e dos efeitos de dominação: trata-se de docilizar através de procedimentos que investem o corpo mais que objetivam a alma e o autocontrole, a interiorização da norma.

Pode-se dizer que a emergência das técnicas disciplinares materializa uma nova estratégia de exercício do poder de castigar; a questão, aqui, não é punir menos, mas punir melhor, com mais universalidade - extensão e profundidade.

R. Inter. Interdisc. INTERthesis, Florianópolis, v.12, n.2, p.34-54, Jul-Dez. 2015 
Contudo, alerta Passetti (2004, p. 154) que a sociedade disciplinar

[...] criou positividades de poder, caracterizando-se como uma sociedade diferente da sociedade de soberania que a antecedeu e não suprimiu, acrescentando-Ihe novos trajetos. Da mesma maneira, a sociedade de controle não destrói a que a antecedeu: redimensiona o domínio de forma mais sutil.

As disciplinas espelham um conjunto de "métodos que permitem o controle minucioso das operações do corpo, que realizam a sujeição constante de suas forças e Ihes impõe uma relação de docilidade-utilidade" (FOUCAULT, 2013, p. 133). Em outras palavras, a disciplina inaugura um conjunto de invenções técnicas voltadas para a extensão útil das multiplicidades, de modo que o poder seja regido de forma mais racional e econômico.

As disciplinas se impõem por meio de uma distribuição corporal nos espaços (p. 137) e devem sua eficácia aos instrumentos denominados como "recursos para o bom adestramento", quais sejam: 1) vigilância hierárquica; 2) sanção normalizadora; 3) exame (FOUCAULT, 2013). Nos três casos, a dinâmica de funcionamento da disciplina supõe uma distribuição racionalizada dos indivíduos no espaço e, ao mesmo tempo, um gerenciamento de suas ações no tempo.

O poder que opera o detalhe via encarceramento disciplinar, aparentando o funcionamento de um laboratório, coloca saber e poder em interação simbiótica, dinâmica, na medida em que o poder investido sobre o interno cresce de forma diretamente proporcional ao saber obtido pela instituição. Em outros termos, "não há relação de poder sem constituição correlata de um campo de saber, nem saber que não suponha e não constitua ao mesmo tempo relações de poder" (FOUCAULT, 2013, p. 30). Ou ainda, "todo ponto de exercício de poder é, ao mesmo tempo, um lugar de formação de saber" (MACHADO, 1979, XXI).

No contexto dos dispositivos disciplinares, talvez seja a estratégia panóptica ver sem ser visto - o modelo que expressa o mais alto grau de eficácia da vigilância na sociedade moderna. O panóptico impõe-se ao indivíduo visando produzir "um estado consciente e permanente de visibilidade que assegure o funcionamento automático do poder. Fazer com que a vigilância seja permanente em seus efeitos, mesmo se é descontínua em sua ação" (FOUCAULT, 2013, p. 191).

Com este tipo de dispositivo, temos uma inversão do princípio da masmorra e de suas funções: "trancar, privar de luz e esconder". Na passagem das práticas de R. Inter. Interdisc. INTERthesis, Florianópolis, v.12, n.2, p.34-54, Jul-Dez. 2015 
soberania (espetaculares) para as práticas disciplinares só a primeira função se conserva, a de trancar, sendo o panóptico, nesse contexto, um dispositivo que autonomiza e desinvidualiza o poder. Aqui, pouco importa quem exerce o poder, posto que qualquer individuo, em princípio, pode ser o observador oculto e, assim, fazer a máquina de poder funcionar. A importância deste modelo de vigilância assume relevância não só na modernidade, mas também nos estudos atuais sobre o tema:

A relação do panóptico com a vigilância tem sido minuciosamente ensaiada. De fato, esse deve ser o conceito teórico mais discutido e debatido. $O$ ímpeto panóptico é tornar tudo visível; é o desejo e a condução a um olhar generalizado, para ajustar o corpo pela técnica e para gerar regimes de autodisciplina pela incerteza (LYON, 2010, p. 127).

O olhar onipotente e onipresente do inspetor permite que tal arquitetura de vigilância, com formato de pirâmide, torne-se análoga a uma prisão, cujos detentos são conduzidos e mantidos em regime de sujeição e obediência por meio de uma visibilidade meticulosa. É por isto que o panóptico desdobra-se como "uma máquina maravilhosa que, a partir dos desejos mais diversos, fabrica efeitos homogêneos de poder" (FOUCAULT, 2013, p. 192).

Em sentido confluente, Deleuze (2011, p. 42) infere que o panoptismo caracteriza-se por ser "um agenciamento visual e um meio luminoso do qual o vigia pode ver tudo sem ser visto, no qual os detidos podem ser vistos, a cada instante, sem verem a si próprios (torre central e células periféricas)". Ao funcionar como uma espécie de microscópio do comportamento (FOUCAULT, 2013, p. 167) ou como um laboratório do poder (p. 194), o maquinário de controle do panóptico se insere socialmente mediante duas dimensões inevitavelmente articuladas, uma mais concreta e outra mais abstrata. A dupla faceta do panoptismo disciplinar é bem expressa nos seguintes termos deleuzianos:

[...] quando Foucault define o Panoptismo, ora ele o determina concretamente, como um agenciamento óptico ou luminoso que caracteriza a prisão, ora abstratamente, como uma máquina que não apenas se aplica a uma matéria visível em geral (oficina, quartel, escola, hospital, tanto quanto a prisão), mas atravessa geralmente todas as funções enunciáveis. A fórmula abstrata do Panoptismo não é mais, então, ver sem ser visto, mas impor uma conduta qualquer a uma multiplicidade humana qualquer (DELEUZE, 2011, p. 43).

Trata-se de pensar o diagrama, essa "máquina abstrata" (DELEUZE, 2011, p. 44), como mecanismo que existiu mesmo nas sociedades antigas (de soberania),

R. Inter. Interdisc. INTERthesis, Florianópolis, v.12, n.2, p.34-54, Jul-Dez. 2015 
ainda que com outras matérias e funções. O diagrama, enquanto construção histórica e com capacidade eminente de atualização, "é altamente instável ou fluido, não pára de misturar matérias e funções de modo a constituir mutações" (DELEUZE, 2011, p. 44-45). O diagrama disciplinar, em sua fórmula abstrata, volta-se para uma ordenação das multiplicidades humanas, utilizando-as, tornando-as úteis, manobrando as potencialidades de suas interconexões, dos conflitos subjetivos e das produções coletivas.

Foucault (2008), em seus movimentos reflexivos, foi além da abordagem descrita no Vigiar e Punir, passando a se concentrar numa outra mutação ocorrida no seio do capitalismo. Se nas sociedades disciplinares o foco do poder estava no individuo, exercendo-se um controle mais micrológico e individualizante, nas sociedades biopolíticas o controle se estende para a população, ampliando as estratégias de vigilância e os efeitos de dominação para além dos limites territoriais do Estado-nação.

Nesse contexto de vigilância global, a noção de controle em Deleuze (1992) está diretamente ligada à questão biopolítica em Foucault (1988). Isto pode ser dito na medida em que "só a sociedade de controle está apta a adotar o contexto biopolitico como terreno exclusivo de referência" (HARDT \& NEGRI, 2006, p. 43). A transição das sociedades disciplinares para as atuais, de controle, cria uma situação de domínio que pretende ser completo, demarcando a eclosão de um novo regime de poder - o biopoder:

O poder só pode obter um domínio efetivo sobre a vida inteira da população tornando-se uma função integrante e vital que todo individuo adota e reativa por espontânea vontade. A mais alta função desse poder é de investir a vida por inteiro, e sua primeira tarefa é administrá-la (HARDT; NEGRI, 2004, p. 162).

Operando sobre a vida, rastreando as condutas e registrando o "ethos" do sujeito contemporâneo, o controle contemporâneo conforma a multidão de singularidades, buscando torná-las úteis e produtivas em termos econômicos, ao passo que dóceis e monolíticas em termos políticos. Pensando assim, as relações de poder biopolíticas forjaram uma realidade na qual o propósito único será a manutenção e reprodução da vida. As operações do biopoder redimensionam o projeto homogeneizante para além das fronteiras da nação, apoiando-se na retórica positiva e despolitizante da modernidade tecnológica e da globalização. 
Para Lazzarato (2006, p. 73):

O biopoder é uma modalidade de ação que, como as disciplinas, é endereçada a uma multiplicidade qualquer. As técnicas disciplinares transformam os corpos, ao passo que as tecnologias biopolíticas se dirigem a uma multiplicidade enquanto massa global, investida de processos coletivos específicos da vida, como o nascimento, a morte, a produção, a doença. As técnicas disciplinares conhecem apenas o corpo e o individuo, enquanto o biopoder visa à população, ao homem enquanto espécie e, no limite, como Foucault vai dizer em um de seus cursos, o homem enquanto mente.

Nas sociedades de controle, a expansão do capitalismo cognitivo fez nascer uma onda de controle que atravessa toda a malha social. Da casa, da sala, do recinto mais privado à praça pública, o "dever de vigilância" passa a ser estendido numa dinâmica extensiva horizontal para captar não só os criminosos, mas a todos os indivíduos indiscriminadamente, visando neutralizar todo o "perigo" possível.

Do global para o local, torna-se oportuno contar com a avaliação de pesquisadores brasileiros que perceberam a necessidade de operacionalizar contribuições empíricas no âmbito das nossas cidades. Lucas Melgaço (2010), tendo por base as reflexões de Milton Santos, argumenta que a racionalização do espaço via câmeras de vigilância segue o objetivo de tornar a cidade controlada e previsível, negando-se, neste mesmo processo, o potencial criativo que decorre das relações conflituosas entre os sujeitos sociais. Porém, o mesmo autor pondera que o posicionamento fatalista de que "tudo está controlado e que não há saída" deve ser visto com mais cuidado, pois a resistência criativa da qual nos falou Deleuze (1992) também emerge dentre os novos arranjos do capitalismo pós-fordista.

Contudo, o processo de subversão da lógica racionalista encontra nas narrativas sociais a titulação de um mal eminente, talvez porque a resistência mantém relação significativa com alguns conceitos que questionam o projeto humanista, tais como: devir, transformação, trevas, profundidade, horizontalidade. No caso da videovigilância, é possível pensá-la como um dispositivo que assume uma faceta moral que produz, incansavelmente, novas formas de manifestação do poder: "nessa mesma linha de oposições produzidas, como essa entre o Certo e o Errado, os dispositivos tecnológicos de vigilância vão agregando outras, tais como: o Bem e o Mal, a Ordem e a Desordem, a Vítima e o Criminoso" (CASTRO \& PEDRO, 2010, p. 57). Estas polarizações discursivas, de cunho moral e criminal, parecem justificar os fenômenos de exclusão e segregação social em muitos processos R. Inter. Interdisc. INTERthesis, Florianópolis, v.12, n.2, p.34-54, Jul-Dez. 2015 
urbanos contemporâneos, os quais costumam aparecer cotidianamente nas cidades brasileiras como um movimento insidioso de promoção e equilíbrio democrático.

Em sentido convergente a Melgaço (2010), com outro tipo de abordagem, Marta Kanashiro (2006) estudou a forma como os processos de Revitalização Urbana emergem em conexão com práticas de videovigilância, fazendo emergir um efeito político-estético de desaparecimento do errante - aquele se destaca do fluxo na multidão (KANASHIRO, 2006). Grosso modo, esta autora percebeu que a vigilância visual foi implantada com o duplo objetivo de eliminar os "indesejáveis" e disciplinar os "desejáveis" de determinados espaços públicos da cidade de São Paulo.

Corroborando com a crítica das sociedades de controle, Kanashiro (2006, p. 79) acrescenta que os dispositivos de videovigilância carregam como bojo não um incentivo aos conflitos, mas a neutralização destes, participando ativamente de um conjunto de programas, urbanísticos e midiáticos, em que a cidade é projetada como um sistema total de iguais. Daí que a função dos dispositivos produtores de imagens visa estabelecer uma imposição da exposição que funcione produzindo efeitos inibidores de resistências.

\section{DESENHOS DE RESISTÊNCIA NAS CIDADES BRASILEIRAS}

Muito se tem discutido sobre os impactos e efeitos das sociedades de controle e as tecnologias de comunicação e informação. Há toda uma gradação de pesquisas, quantitativas e qualitativas, que indicam as particularidades de cada contexto urbano pesquisado, destacando as fragilidades dos sistemas de controle na produção da segurança, assim como as percepções daqueles que vigiam, dos que são vigiados e das características técnicas que subsidiam o exercício do controle ${ }^{2}$.

Conforme propomos neste texto, os desenhos de resistência conformam um conjunto de procedimentos (ZORZO, 2007), ainda que pontuais, em que se observa uma estratégia de recusa criativa ao ambiente de controle que sufoca a cidade contemporânea (VIRILIO, 1993). Se concordarmos que os dispositivos de controle constituem um conjunto de práticas que visam potencializar a vida de alguns e

2 BRUNO (2013), SAMPAIO (2014), TREVISAN, FIRMINO E MOURA JUNIOR (2009), ZIMMER (2009), entre outros.

R. Inter. Interdisc. INTERthesis, Florianópolis, v.12, n.2, p.34-54, Jul-Dez. 2015 
eliminar ou conter a experimentação da vida pelos indesejáveis, podemos dizer que os movimentos de resistência elaboram um efeito de contra-violência. Com esta primeira premissa, passemos a trazer o registro dos desenhos de resistência.

Figura 1 - Avenida Mário Covas Júnior, perto do Mauá Plaza Shopping, Mauá - SP.

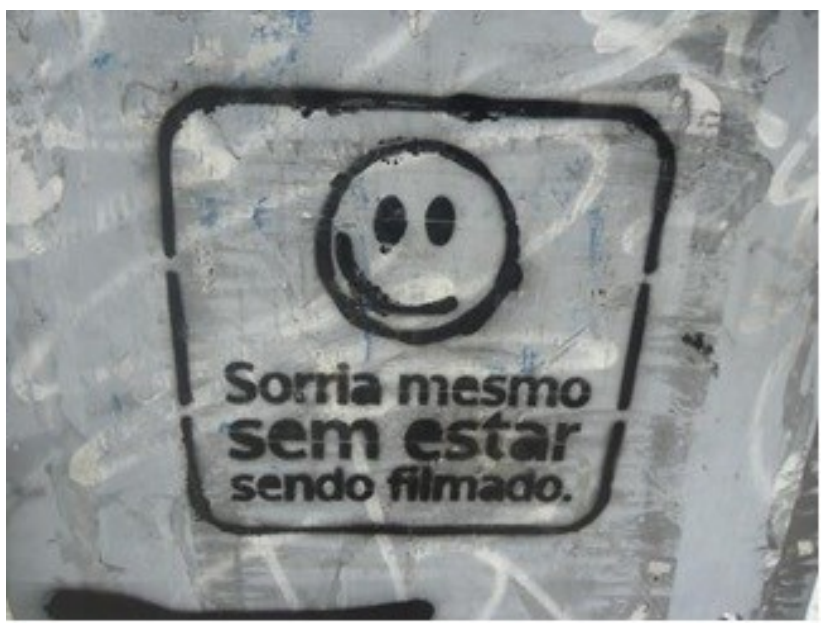

Fonte: http://olheosmuros.tumblr.com/

Figura 2 - Avenida Borges de Medeiros, Porto Alegre - RS

Fonte: http://olheosmuros.tumblr.com/

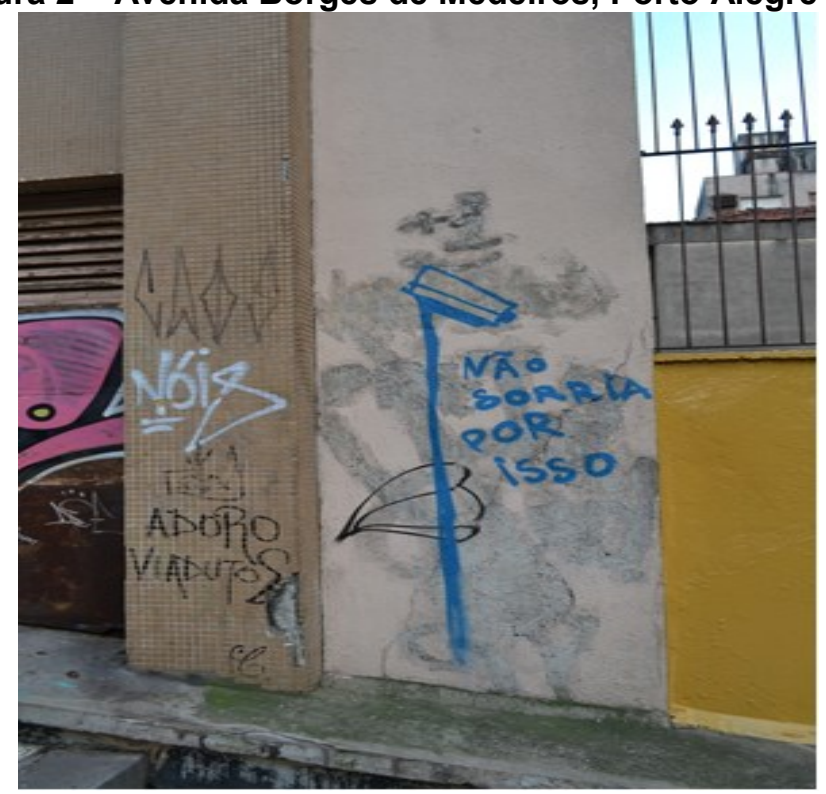

Como se vê, os desenhos 1 e 2 elaboram uma apropriação subversiva da expressão "sorria, você está sendo filmado". Por trás dessa simples expressão cristaliza-se uma situação que caracteriza as relações sociais e a democracia no início do século XXI. Por todo o ambiente construído, as câmeras de vídeo gravam as atividades realizadas em espaços públicos e privados, visando manter a suposta 
segurança. A gravação dos vídeos de segurança segue uma lógica social. Para quem filma, os objetivos são, geralmente, de policiamento e controle social. Para os que estão sendo filmados, no entanto, os efeitos são imprevisíveis e ambivalentes.

Nas cenas sob videovigilância, diferente da interação presencial que se consome em cada atividade realizada, fica um resíduo na forma de imagem, que se deposita em um arquivo. Dependendo do resíduo da imagem social registrada, a videosegurança tanto pode se instituir como um serviço público, quanto um abuso das instituições e sujeitos que a empregam. Evidentemente, com a introdução cotidiana das gravações, desencadeia-se um efeito de rede, pois as câmeras se acumulam e dão base para a criação de um banco de dados que se prolonga e se atualiza com o transcorrer do tempo (ZORZO; SAMPAIO, 2012).

Podemos, ainda, observar que a formação discursiva do SVSF", especialmente o uso do verbo sorrir, "pode estar antecipando e tentando suspender uma reação adversa por parte de quem está sendo filmado". Em verdade, o que realmente espera-se provocar não é um sorriso, mas sim um bom comportamento" (RODRIGUES, 2005, p. 6).

De forma comum, os desenhos desvelam uma recusa "suave" ao dispositivo de vigilância. Esta recusa parece se dar na forma de ironia, onde possivelmente o agente, ao deparar-se com o imperativo do SVSF, atribui-lhe um sentido adverso, valendo-se de uma civilidade dissimulada (BHABHA, 1997). Com isso, parece-me que o efeito desse desenho de resistência não é simplesmente sugerir que todos devem sorrir, mas que o "dever sorrir" na sociedade videovigiada traz consigo um interessante movimento irônico, exigindo um comportamento duplo do vigiado - ou seja, apesar do mal que sente, o sujeito deve sorrir, pois está sendo vigiado e poderá ser observado nos atos mais comezinhos de sua vida íntima.

Por sua vez, o sugestivo "não sorria por isso" faz pensar que a vigilância das câmeras possui efeitos contrários em relação àqueles que são alegados. Se pensarmos que o sorriso é um privilégio dos humanos, então, o "não sorrir" pode inserir o sujeito numa zona nada confortável de criminoso antes do suposto crime, culpado antes da suposta culpa. Estaríamos, por assim dizer, diante de uma corrida securitária que fabrica suspeitos de maneira contínua, ostensiva e indiscriminada.

\footnotetext{
${ }^{3}$ Utiliza-se essa sigla como referência ao "Sorria, você está sendo filmado".

R. Inter. Interdisc. INTERthesis, Florianópolis, v.12, n.2, p.34-54, Jul-Dez. 2015
} 
Por outro lado, veja-se o desenho da figura 3, que chama atenção para uma mudança nas práticas de vigilância na sociedade contemporânea:

Figura 3 - Em Santa Teresa, Rio de Janeiro

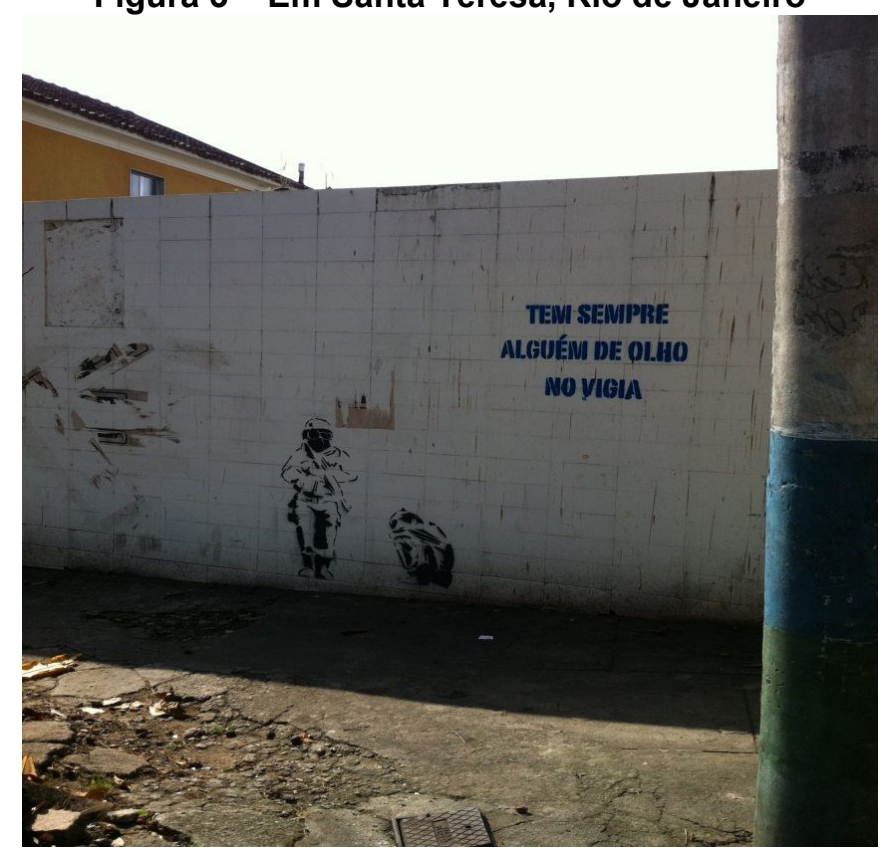

Fonte: http://olheosmuros.tumblr.com/

O alerta do "tem sempre alguém de olho no vigia" remete diretamente ao caráter tecnológico e descentralizado da vigilância atual. Conforme indicou Bogard (2006), a vigilância e o controle contemporâneos são menos sujeitos a restrições espaciais, portanto, não se reduzem a uma lógica geométrica fechada de enclausuramento e disciplina. Isto ocorre porque o poder se tornou inteiramente biopolítico e, com efeito, ele é "expresso como um controle que se estende pelas profundezas da consciência e dos corpos da população - e ao mesmo tempo através da totalidade das relações sociais" (HARDT; NEGRI, 2006, p. 43-44).

"Na cidade que controla e que é controlada" (MOURA, 2006), uma imagem como essa amplia a discussão sobre a suspeição generalizada que marca a cidade contemporânea. $\mathrm{O}$ fato de quem vigia ser também vigiado reflete de certa maneira a própria analítica do poder como relação da qual nos falou Foucault (2000). Na esteira do filósofo Nietzsche, Foucault apostou em uma compreensão mais ampla do poder, que não se reduz ao poder central do Estado e do aparelho judiciário; um poder que, dada a complexidade das relações sociais, tem sentido de repressão, mas, sobretudo, produção de saberes, práticas e técnicas. Ao desaguar por meios e 
vias diversas, o poder permite um devir incessante dos sujeitos e das características das cidades.

Com essa compreensão multifacetada do poder, Foucault (1993) abre margem para a possibilidade de os esquemas de vigilância se tornarem mais distribuídos e difusos (BRUNO, 2013), o que explicaria a extensão da vigilância para além dos espaços fechados e, portanto, chegando as tecnologias de vigilância e controle ao ar livre, mas também nas tecnologias de informação e de vigilância para consumo. Essa lógica se espalha, pois há na cidade contemporânea um complexo ambiente midiático, mediado por câmeras e outros inúmeros dispositivos tecnológicos.

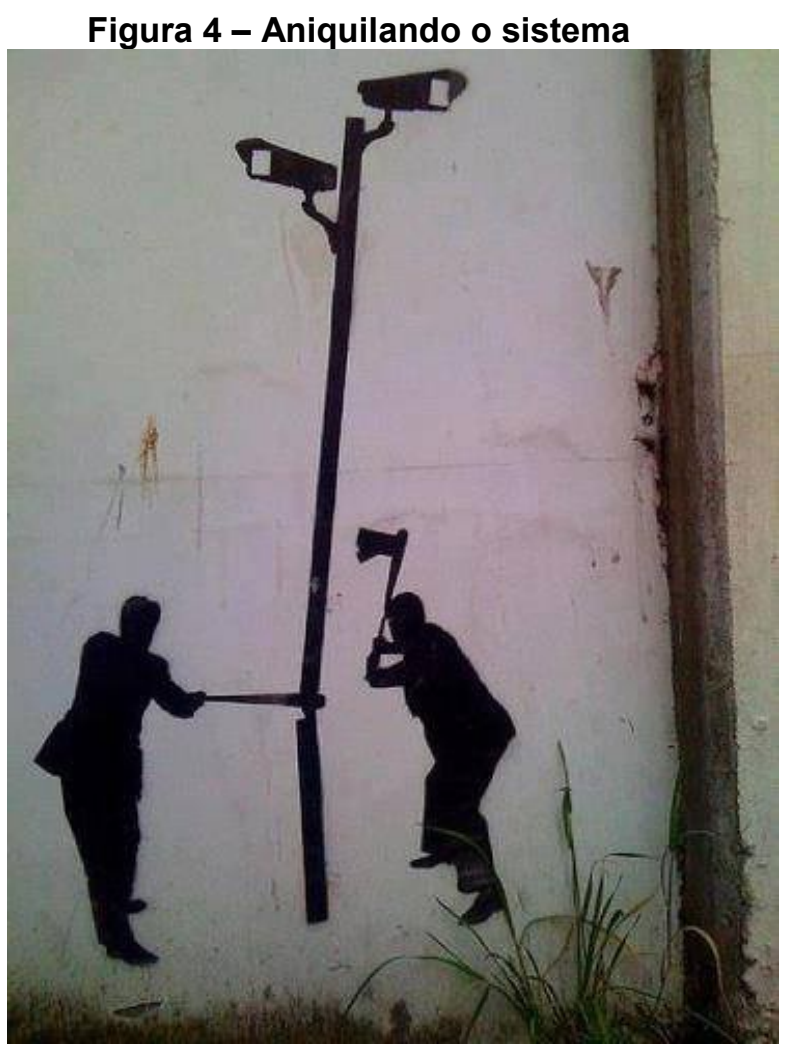

Fonte: https://www.facebook.com/photo.php?fbid=516995741671032\&set=pb.249780145059261.2207520000.1368115444.\&type=3\&theater

Soa irônico e curioso que o desenho da figura acima ganhe expressão no Facebook, uma rede de relacionamento e vigilância digital bastante popularizada e desejada na atualidade. Não obstante, isso é possível de compreender na medida em que a resistência não tende a se dar fora do controle, mas dentro dele_(HARDT; NEGRI, 2006). O desenho da figura 4 é bem interessante porque, neste caso, demonstra-se a relação dinâmica entre os dispositivos de poder na sociedade. Dois 
dispositivos, o Facebook e a videovigilância, operando de forma articulada e complementar: o desenho evidencia que o primeiro dispositivo serviu de espaço potencial para uma negação do segundo. Se os desenhos anteriores expõem uma resistência mais "suave", este desenho propõe uma subversão mais radical das forças de controle.

No entanto, o "poder do não" que este desenho quer indicar pode ser reduzido, apressadamente, a mero ato de vandalismo, supostamente simplista e injustificado. Quando isto ocorre, "o marginal é, assim, socialmente produzido" (MELGAÇO, 2010, p. 131), assumindo a imagem de algo que é ruim e corrupto por natureza. Quando se investe na aniquilação do sistema, assume-se o risco de ser avaliado segundo os piores parâmetros: aniquilar a câmera, fazer cessar seus objetivos, faz do suspeito criminoso, capaz de qualquer prática criminosa - inimigo, portanto, da suposta segurança.

Quando o "outro" é eliminado, a sociedade experimenta uma espécie de gozo perverso (ZIZEK \& DALY, 2006) que enxerga nessa eliminação o caminho mais fácil para o exercício de uma política democrática emancipadora. Ou seja, a morte, manifesta-se nessas sociedades biopolíticas através dos processos de exclusão e segregação do "outro". A morte do outro é o caminho perverso de tornar a vida sadia, plena, estável e harmônica (FOUCAULT, 1988; 2008). Tendo isso em vista, a resistência com certas doses de força tem o sentido de radicalizar aquilo que tende a manter o status quo e a reprodução da desigualdade, logo, da violência.

\section{CONSIDERAÇÕES SOBRE A RECUSA CRIATIVA}

O desenho pensado neste trabalho inscreve-se na cidade como potência política de resistência. Trabalhar esta outra perspectiva é importante na medida em que as sociedades atuais nos colocam diante "de uma profusão de fluxos anuladores de resistências, às vezes invisíveis, e em velocidades estonteantes" (PASSETTI, 2011, p. 54). A noção de resistência, tomada no sentido deleuziano de criação (DELEUZE, 1992), me parece extremamente oportuna para o pensamento político contemporâneo, inclusive como forma de reafirmar que a pulsação e trânsito 
do sujeito contemporâneo não cabem em categorias fixas e estáveis, prédeterminadas e supostamente iluminadas por forças metafísicas (WILLIAMS, 2012).

Através dos desenhos apresentados pode-se gerar uma noção sobre a emergência das práticas de resistência que se dão pela via do registro e da visualidade. Nos procedimentos de recusa, ficou colocado o modo como os sujeitos elaboram formas políticas de recusa à vigilância do ambiente urbano. Neste mote reflexivo, o desenho é concebido como ação política que envolve uma experimentação marginal da cidade, comparecendo como recurso de afirmação da cultura enquanto campo plural, performático e contraditório, ainda que subsistam as tentativas de homogeneização e domestificação das identidades.

Por sua abertura e certa acessibilidade pela população, os desenhos nos muros passaram, nas últimas décadas, a ser espaço de vigilância pelos poderes instituídos (CAMPOS, 2007). Por conta do seu poderoso efeito comunicativo, o desenho foi reduzido à condição de mero ato de vandalismo, supostamente injustificado do ponto de vista político e carecedor de qualidade pelo viés estético. Os desenhos, muitas vezes nômades e avessos ao capitalismo, foram negados enquanto expressões que envolvem subjetividades libertárias, descontinuidades eloquentes e desassossegos no âmbito da cultura urbana.

O desenho constitui uma linguagem que incorpora os vários espaços da cidade, portanto, "nasce nas paredes, nos tectos, nas janelas, nas portas, nos caixotes de lixo, nas carruagens de metro ou de comboio, nos vidros e estofos de autocarros entre outros suportes inanimados, que povoam a geografia urbana" (CAMPOS, 2007, p. 253). Qualquer suporte físico dá condições para que o desenho se enraíze e desdobre seus efeitos variados: "qualquer suporte é, à partida legítimo, desde que cumpra o requisito fundamental: esteja no espaço público, independente do estatuto de propriedade, ao dispor de todos" (Ibidem, p. 253). Temos aqui um outro atributo dos desenhos de resistência. Eles não circulam pelos espaços fechados de galerias e elites, mas habitam a efervescência conflitiva do ambiente urbano.

Em seu sentido mais amplo, o desenho "é desregrado e transgressor, como tal, não comporta regras de composição às quais deva cega obediência" (CAMPOS, 2007, p. 257). O desenho é, por definição, uma produção imprevisível que não opõe 
palavra e imagem: ambas não se excluem, são complementares e estão interpenetradas na produção cultural.

É justamente por seguir uma lógica de indeterminação e por não se limitar ao que é possível, que o desenho ainda é muito desprezado por certa parcela da comunidade cientifica; essa que, ao preconizar um cientificismo totalizante, legitima processos de caráter passivo e mistificador do devir criativo. Campos (2007), teorizando sobre as potencialidades do desenho, argumenta que ele pode ser concebido como uma possibilidade do vir a ser, ou, em outras palavras, como o imprevisível que se move na e pela pluralidade cultural. O desenho comparece como potência que transcende o visível, não se limita ao consciente nem tampouco ao racional. O grande problema que perpassa o desenho nos muros é que ele vem sendo minado e desqualificado, fraturado pela predominância de uma racionalidade instrumental.

Em meio aos problemas do pensar instrumental, o desenho, enquanto procedimento que articula o visível e o invisível, estabelece um modo de proceder contra as forças hegemônicas, formulando e refletindo formas inéditas de interação com o espaço e com o outro, contrapondo a força esterilizante do capitalismo. A cidade, se pensada através dos desenhos nos muros, revela-se uma saída ética para contornar, ainda que de forma micro, as forças mecânicas e ideológicas que estão atreladas ao regime de videovigilância das cidades. A grande potência do desenho no contexto aqui tratado é o fato de constituir uma práxis política visual enquanto transgressão, no sentido de que se desdobra comunicando desobediência e recusa da norma (CAMPOS, 2007).

\section{CONSIDERAÇÕES FINAIS}

Esta breve reflexão não possui pretensão nenhuma de esgotar as discussões sobre os desenhos de resistência nas cidades brasileiras. Tratou-se de colocar pequenas questões sobre um tema que ainda não está plenamente posto nas discussões sobre os efeitos antidemocráticos das sociedades de controle. Mesmo com o risco de negligenciar outros elementos, gostaria de registrar algumas ideias que me tocam por ocasião dessa finalização. 
Como viemos tratando, as sociedades atuais nos colocam diante de um quadro de vigilância e visibilidade que atende a efeitos diferenciados, a depender de quem filma, de quem é filmado e de quais intencionalidades estão ligadas ao exercício do controle. De certo modo, esse cenário de visibilidade espetacular vem impulsionar uma alienação da imagem em troca do consumo, o que, por sua vez, reflete uma hipertrofia do aparecer sobre o ser. Nessas cidades superexpostas ${ }^{4}$, aquilo que não se exibe, o próprio cuidado com o "ethos" quando procura se invisibilizar, é visto com desconfiança, pois pressupõe um desvio, algo que induz a pensar que um suspeito, estranho ou desconhecido, está a se manifestar.

Arriscaríamos a dizer que os desenhos que selecionamos têm um sentido de busca por certa invisibilidade nas cidades. Aqui, tornar-se invisível pressupõe um recurso para potencializar atividades criativas que, em muito, dependem de liberdade e espontaneidade. Se é assim, cabe entender o desenho de resistência como aquilo que escapa aos poderes e saberes constituídos, fazendo as estruturas dançarem ao som de pontos de interrogação. Enfim, o desenho constitui um modo de produção de subjetividades que movimenta a cultura como fonte política e estética de uma crítica do mesmo, do idêntico. Os desenhos de resistência não indicam para perguntas limitadas pelas respostas, mas apontam para uma rede de novas problematizações possíveis e contingentes.

Neste sentido, a relevância do estudo vem no sentido de mostrar que, na contramão da cidade videovigiada, existe um processo ascendente de resistência que sobrevive pela via da negação criativa nas sociedades de controle. Os procedimentos de recusa alimentam o processo criativo que desemboca no novo, no inédito, na inventividade de novas "possibilidades de vida". Criar, nesse contexto, volta-se para o sentido de estabelecer "uma relação consigo que nos permita resistir, furtar-nos, fazer a vida ou a morte voltarem-se contra o poder." (DELEUZE, 1992, p.123).

A recusa à cidade videovigiada é algo que eleva-se como movimento que contrapõe o sonho humanista que projeta a cidade como arena homogênea e equilibrada. Convém frisar que a resistência não está no campo das utilidades, das funcionalidades, mas está, por outro lado, no campo da ação política plena e

\footnotetext{
${ }^{4}$ Conforme Virilio (1993).
}

R. Inter. Interdisc. INTERthesis, Florianópolis, v.12, n.2, p.34-54, Jul-Dez. 2015 
experimentativa, em função de ultrapassar aquilo que os dispositivos nos pedem sutilmente ao mesmo tempo que violentamente.

R. Inter. Interdisc. INTERthesis, Florianópolis, v.12, n.2, p.34-54, Jul-Dez. 2015 


\title{
DRAWINGS OF RESISTANCE IN THE VIDEO-SURVEILLED CITY: CONSIDERATIONS ABOUT CREATIVE REFUSAL IN THE CONTEMPORARY BIO-POLITICAL CONTEXT
}

\begin{abstract}
This paper composes considerations about the design of resistance in the contemporary bio-political society. At first, it rescues the discussion of "disciplinary societies" and "controlling societies", in order to raise the creative resistance question as the insurgents flows of Brazilian cities. Moreover, it is possible to define some current political movements that point out to the ambivalent nature of the contemporary bio-politics society.
\end{abstract}

Keywords: Discipline. Control. Video surveillance. Resistance design. Contemporary city.

\section{DIBUJOS DE RESISTENCIA DE EN LA CIUDAD VIDEOVIGILADA: CONSIDERACIONES ACERCA DEL RECHAZO CREATIVO EN EL CONTEXTO BIOPOLITICO CONTEMPORÁNEO}

\section{Resumen}

El texto teje algunas consideraciones sobre el dibujo de resistencia en la sociedad biopolítica contemporánea. Inicialmente, retoma la discusión sobre las "sociedades disciplinarias" y "sociedades de control", para posteriormente referirse a la cuestión de la resistencia creativa como flujos insurgentes en las ciudades brasileñas. Con ésto, podemos indicar algunos movimientos políticos actuales que apuntan hacia el carácter ambivalente de la sociedad biopolítica contemporánea.

Palabras clave: Disciplina. Control. Videovigilancia. Dibujos de Resistencia. Ciudad contemporánea. 


\section{REFERÊNCIAS}

ARENDT, Hannah. A condição humana. 10. Ed. Rio de Janeiro: Forense Universitária, 2009.

BHABHA, Homi. O local da cultura. In: Civilidade dissimulada. Belo Horizonte: UFMG, 1998, p. 139-149.

BOGARD, William. Theorizig Surveillance. In Surveillance assemblage and lines of flight, 2006. Ed. Portland, OR: Willam.

BRUNO, Fernanda. Máquinas de ver, modos de ser: vigilância, tecnologia e subjetividade. - Porto Alegre: Sulina, 2013, 190 p.; (Coleção Cibercultura).

CAMPOS, Ricardo. Pintando a cidade: uma abordagem antropológica do graffiti urbano. (Doutoramento em Antropologia), Universidade Aberta, Portugal, 2007.

CASTRO, Rafael Barreto; PEDRO, Rosa Maria Leite. Redes de vigilância: experiência da segurança e da visibilidade articuladas às câmeras de monitoramento urbano. Porto Alegre: Sulina, 2010, p. 36-60.

DELEUZE, Gilles. Conversações. Rio de Janeiro. Editora 34, 1992.

DELEUZE, Gilles. Foucault. Editora brasiliense: São Paulo, 2011.

DELEUZE, Gilles. Deux régimes de fous (textes et entretiens 1975-1995). Paris: Les Éditions de Minuit, 2003.

DUARTE, André. Vidas em risco: crítica do presente em Heidegger, Arendt e Foucault. Rio de Janeiro: Forense Universitária, 2010.

FERREIRA, Lucas Tavares. 0 traçado das redes: etnografia dos grafiteiros e a sociabilidade na metrópole. Dissertação (Mestrado em Ciências Sociais). Universidade Federal de São Carlos, São Paulo, 2006.

FOUCAULT, Michel. Vigiar e Punir. História da violência nas prisões. Petrópolis, Rio R. Inter. Interdisc. INTERthesis, Florianópolis, v.12, n.2, p.34-54, Jul-Dez. 2015 
de Janeiro: Vozes, 2013.

FOUCAULT, Michel. Segurança, Território, População. São Paulo: Martins Fontes, 2008.

FOUCAULT, Michel. História da Sexualidade: a vontade de saber. Rio de Janeiro: Edições Graal, 1988.

FOUCAULT, Michel. Microfísica do Poder. Rio de Janeiro: Graal, 1993.

FOUCAULT, Michel. A sociedade disciplinar em crise (1978). In: Ditos e escritos IV: estratégia, poder-saber. Rio de Janeiro: Forense Universitária, 2003.

FOUCAULT, Michel. Sobre a História da sexualidade. In: Microfísica do poder. Trad. Roberto Machado. Rio de Janeiro: Graal, 2000.

FOUCAULT, Michel. Em defesa da sociedade, curso no Collège de France (1975-1976). São Paulo: Martins Fontes, 2002.

FUCHS, Christian. Como podemos definir vigilância? Matrizes, São Paulo. Juldez, 2011, p. 109-136.

HARDT, Michael; NEGRI, Antônio. Império. 8. Ed. Rio de Janeiro, 2006, p. 42-49.

A produção biopolítica. In: PARENTE, André (Org.).

Tramas da rede: novas dimensões filosóficas, estéticas e políticas da comunicação. Porto Alegre: Sulina, 2004.

MELGAÇO, Lucas. Estudantes sob controle: a racionalização do espaço escolar através do uso de câmeras de vigilância. O social em questão - Ano XV- n 27, 2012.

MELGAÇO, Lucas. Securização Urbana: da psicoesfera do medo à tecnosfera da segurança.2010. 274f. Tese (Doutorado), Universidade de São Paulo, São Paulo, 2010.

KANASHIRO, Marta Mourão. Sorria, você está sendo filmado: as câmeras de 
monitoramento para segurança em São Paulo. 2006. 123f. Dissertação (Mestrado em Sociologia), Instituto de Filosofia e Ciências Humanas, Universidade Estadual de Campinas, Campinas, 2006.

LYON, David. Vigilância e visibilidade: espaço, tecnologia e identificação. Porto Alegre: Sulinas, 2010, p. 115-140.

MACHADO, Roberto (org). Microfísica do Poder (textos, entrevistas de Michel Foucault). Rio de Janeiro: Edições Graal, 1979.

MOURA, Rosa. A cidade vigiada. The Truman Show, de Peter Weir, Vitruvius, 1998.

MOURA, Rosa. Um ensaio sobre o controle da cidade e do cidadão contemporâneo. Revista Cidades. 2006.

PASSETI, Edson. Segurança, confiança e tolerância: comandos da sociedade de controle. São Paulo em Perspectiva, 18(1): 151-160, 2004.

Fluxos libertários e segurança. Revista Verve, v. 20. 2011, p.

49-78.

RODRIGUES, Cristina Zanella. Discurso da vigilância na escola: o caso do sorria você está sendo filmado. Congresso Internacional Linguagem e Interação, 2005, São Leopoldo. Congresso Internacional Linguagem e Interação, 2005.

RUIZ, Castor. Os paradoxos do imaginário. Editora Unisinos, 2003, p. 29-47.

SAMPAIO, Eledison de Souza. Práticas de videovigilância na cidade contemporânea: o caso da UFBA - Campus de Ondina. 2014. 131f. Dissertação (Mestrado em Desenho, Cultura e Interatividade) - Departamento de Letras e Artes, Universidade Estadual de Feira de Santana, Feira de Santana (BA), 2014.

SAMPAIO, Eledison; ZORZO, Francisco. Problematizações sobre videovigilância. II Encontro de Estudos Baiano de Estudos em Cultura, UFRB, 2012.

VIRILIO, Paul. A cidade superexposta. In: O espaço crítico. Ed. 34: Rio de Janeiro, R. Inter. Interdisc. INTERthesis, Florianópolis, v.12, n.2, p.34-54, Jul-Dez. 2015 
1993, p.7-21.

ZIZEK, Slavoj e DALY, Glyn. Arriscar o impossível: conversas com Zizek. São Paulo: Martins fontes, 2006.

ZORZO, Francisco Antônio. Procedimentos visuais: alguns problemas do desenho contemporâneo. Anais do Graphica, 2007.

WILLIAMS, James. Pós-estruturalismo como filosofia da diferença. Diferença e repetição, de Gilles Deleuze. 2012.

\section{Artigo}

Recebido em 01 de junho de 2015

Aceito em 20 de novembro de 2015 